\title{
Study regarding the use of movement games in order to improve coordination abilities in primary school pupils
}

\author{
Talaghir Laurentiu-Gabriel ${ }^{1, \text { a }}$ and Cherepov Evgeny ${ }^{2}$ \\ ${ }^{1}$ University „Dunarea de Jos”,Domneasca Street, no. 46, 800008, Galati, Romania \\ 2 South Ural State University, Lenin's Street no. 76, Chelyabinsk, 454080, Russian
}

\begin{abstract}
The purpose of the research, performed during the school year 2015 - 2016, was to observe the role of movement games during the PE class, carried out with primary school pupils. The aim of the present paper is to present the way in which we influenced the coordination skill manifestation indicators so that they are suited to the pupils' age possibilities. The games were combined and we used two games during each practical PE class. In order to achieve this, we changed the working method at the structure level of the lesson. Thus, in the second part of the lesson, which includes types of walking and running in order to engage the body in the effort, we used movement games. As an assessment test, we used the trial "Throw at a vertical target". This trial tests the coordination skill (the dexterity) within the school assessment system. The results obtained in the trials were statistically processed by means of the SPSS 23.0 program. The results indicated a significant progress for the group of girls and an insignificant progress for the groups of boys.
\end{abstract}

\section{Introduction}

The education system represents the coherent ensemble of the school institutions of all levels, specialisations and forms, which is designed, organized and functions on the basis of a number of general educational principles, with an organisational character, and some of them with a legal character, as well as of some educational standards [1].

Physical Education is a school subject, component of the education and teaching process, together with other subjects within the compulsory school curriculum. The importance of PE was and is permanently emphasized by specialists in the domain. The physical and emotional development of the young generation strongly relies on a healthy body. The methodology of organising and conducting PE classes in pre-university education [13] includes Physical Education and Sport among the global education components, their content having a strong influence on the health, development and growth of the body, as it helps in developing motor skills and emotional processes and in socializing.

\footnotetext{
${ }^{\text {a }}$ Corresponding author: gtalaghir@ugal.ro
} 
Physical Education is present in the educational and teaching process from very early ages (6 years old) until university studies, when the individual has already become an adult ( $\geq 20$ years old). This very long period of time during which PE follows the transformation process of the child into an adult speaks for itself in point of the beneficial effects it has on the body [21].

The evolution of PE as a school subject has been permanently achieved with the help of the curriculum. In Romania, beginning with the school year 2015-2016, a new curriculum for primary school was introduced $[22,23]$. This curriculum is trying to shift focus from objective-centred learning to competence-centred learning. This is one of the directions which are considered a priority for Romanian education. The new curriculum intends, at least at a conceptual level, to orient students' skills towards the pleasure of practising physical exercises as a means of preserving health. The aspects regarding the performance achieved within the school physical education process are outweighed by the new curricular guidelines [20].

Concerns regarding curricular evolution are also topical at an international level. Specialists in the domain around the world agree with the idea of adapting curricula to the reality and evolution of society $[3 ; 9,15,18,26]$. Also, some authors highlight the importance of the behavioural component and the role that PE has in shaping it $[5,6,17]$.

The specificity of PE classes is different from the other school subjects regarding the content, the structure of the lesson, the activity organisation methodology, the location, the dynamics or the learning particularities [8].

In addition to shaping some skills and competences referring to health and personal hygiene, the school PE classes are fundamentally oriented towards shaping some motor skills, on the one hand, and improving the motor skill manifestation indicators, on the other hand. These two components condition each other. Most often than not, a low level of motor skill index manifestation determines a delay in learning a skill or even the impossibility to learn it.

By taking into consideration this truth, the specialists from the domain are permanently searching for new and attractive solutions, which could more easily lead to the development of motor skills $[4,19]$.

From this perspective, a great number of specialists agree that movement games, or games in general, as a form and means of education, can have an extremely positive effect on young age pupils $[2,14,16,25,27]$.

The improvement of the coordination skill indicators (dexterity) is closely correlated with psychomotricity and the spatial and temporal orientation. In order to achieve this, the games used during primary school education are beneficial. The activities proposed to pupils will be accessible. The concern for increasing the variety of such programs, which focus on this skill, can also be found in the domain-specific literature $[7,10,11,12]$.

In theory, in the physical education school curriculum from Romania, the improvement of the coordination skills in primary school pupils is reflected as a permanent concern through the entire school year. Also, the other motor skills, together with the skills specific to certain sport branches are to be found in the annual planning document drawn up by teachers. In practice, at the level of the lesson plans, the subjects that contain exercises or activities which contribute to the increase of the coordination skill indicators are not found very often.

Accordingly, in the present research, we proposed a number of movement games, which could be used in practice during PE classes in order to improve coordination skills (dexterity). The present paper is the result of the equal contribution of all authors. 


\section{Procedures}

The research activity was performed in Secondary School no. 18, Galaţi, during school year 2015-2016. The subjects with whom we worked within the experiment were pupils in the $3^{\text {rd }}$ grade. There was a total number of 59 pupils involved in the research, out of which there were 29 boys and 30 girls. Within the experiment we used movement games, whose aim was to improve the motor skills manifestation indicators.

In the present paper we shall present the results and discussions connected with the development of coordination skills. The results recorded for the other motor skills were presented in different papers.

The data was collected separately for each motor skill, for which we used a combination of motor games, specific to the skill for which they were proposed.

The results recorded for each motor skill were analysed an interpreted with the help of the statistical program SPSS 23.0. This led to a more accurate reflection of the influence the games proposed within the experiment had on the respective motor skill.

A number of 12 movement games were selected in order to increase the coordination skill indicators (the dexterity). They were used during the entire school year. The implementation method was different. We used one or two movement games in order to develop dexterity within each lesson from the curriculum. They were used at the beginning of the lesson, during the first part of the lesson. For this, the structure of the lesson was changed, that is the second moment of the lesson "preparing the body for effort" was replaced by the proposed games used to improve dexterity.

The control group performed the activities from the planning documents approved by the school management at the beginning of the school year.

The assessment trial used was called "Throw at a vertical target". The trial took place behind a line drawn on the ground and consisted in throwing an oina ball, with one hand above the shoulder, at a vertical target having the width of $0.5 \mathrm{~m}$ and height of $2 \mathrm{~m}$ and being situated at a distance of $2 \mathrm{~m}$. Five executions were performed and the results were recorded. The assessment trial was performed at the beginning and at the end of the school year.

Here are some movement games used to develop coordination skills, as part of the working procedure used. These games were coded and combined among them in view of creating diversity during the entire school year.

\section{Games for developing the coordination skill (dexterity)}

Game no. 1 "THE DEXTEROUS PUPILS" (I.1)

Description: The pupils are scattered on the field, with their hands behind their backs, holding a handkerchief (a piece of string). At the first whistle, they will run on the field as they please, having their hands behind their backs all the time. At the second whistle, they will stop and they will tie around their knees the string and they will run to a preestablished place. The pupil who arrives first at the pre-established place, with the string tied under his/her knee is the winner of the game. The most dexterous pupils are those who have been ranked most times among the first four.

Game no. 2 ,THE BUILDERS” (I.2)

Description: The pupils are scattered on the field. Following the indication "Let's build a square quickly", they must gather and make a square with right sides. At the teacher's whistle, they scatter again on the field. Then, they are asked to build a tram track as quickly as they can (they must form two rows), then a tractor wheel etc. The pupils who organised faster, proved to be good builders. In order to stimulate them more, they can be divided into groups, each group having the name of one building yard. In this case, the result will focus on one group. 
Game no. 3 “THE TRAIN CROSSES THE BRIDGE” (I.3)

Description: The pupils are arranged on two rows in front of the gymnastics bench. They will go one after the other on the gymnastics bench and, then, they will come back to their places. The action is repeated twice. The same exercise is afterwards repeated twice or three times, but with the arms held raised sideways and with a book or a notebook on the head. The same exercise is repeated two or three times by amply rotating the arms. The same exercise is repeated by using the narrow part of the gymnastics bench.

Game no. 4 "THE GOALKEEPERS' GAME” (I.4)

Description: From a sitting position, the children, in pairs, will throw the ball to each other, trying not to drop it. The one that succeeds in performing well, will be declared the best goalkeeper. From a sitting position, the same game will be repeated, by insisting on the throwing position (from the chest). When the throwing and the catching become more accurate, the exercise is performed under the form of a contest. The pairs that manage to catch and throw the ball for 10-15 times without dropping it will be declared champion.

Game no. 5 "THE PAIR RACE” (I.5)

Description: The pupils are arranged on two rows, in pairs, behind the start line. At the teacher's whistle, they throw the ball to each other, in movement (they will have to throw the ball as soon as they catch it) until the pre-established place, from where they come back in the same manner. The game ends when all the pairs execute the required action, i.e. throwing and catching the ball while in movement. During a second repetition, the same action is performed while jogging.

Game no. 6 "THE TRAVELLING BALL" (I.6)

Description: The pupils are divided into 6-8 pupils and they are arranged behind a line. The teams are at a distance of 3-4 steps. The distance between the players has an arm length when the ball is offered. The first player from each team receives one, preferably bigger, ball. The game consists in transmitting the ball from player to player, from the first one to the last. When the ball reaches the last player, he runs with the ball in front of the row; the game continues in this way until the first player comes again in front of the row. Offering procedures: with arms stretched forward, with the arms stretched out in the back, with the legs apart, between the legs, by means of a lateral twist.

Game no. 7 "THE BALL ON THE BRIDGE" (I.7)

Description: The pupils are divided into teams of 6-8 pupils and they are aligned behind a line. The teams are at a distance of 3-4 steps and the distance between the players has an arm length. The first player from each team has a ball which, at the beginning whistle, will pass over the head to the pupil behind him who, in its turn, will pass it forward. When the ball reaches the last player, he comes in front and the game continues until the first pupil will be in front again. The team that finishes first is the winning team.

Game no. 8 "HARVESTING THE CROP" (I.8)

Description: The pupils are divided into 4-6 teams. Each team will have two baskets, one at the start line, in which there are 3-4 small balls and the other, put in front of each row at a distance of 20-25 m. At the teacher's whistle, the first pupil from each row runs with the ball basket to the other empty basket. He loads the balls in the basket and brings it to the next pupil. The game repeats until all the pupils manage to perform the same action.

Game no. 9 "THE DOG AND THE CAT" (I.9)

Description: The pupils are placed in a circle, facing inward (they are allowed to stay with their feet crossed). Two balls of two different colours (or two small objects) represent one, "the cat" and the other one, the coloured one, "the dog". "The cat" is passed around the circle, from hand to hand, without omitting any player. After 6 children, the dog" comes into the play, which is passed from hand to hand in the same direction, with the aim of catching "the cat". The player in whose hand "the dog" catches "the cat" is eliminated from 
the game. The ones that manage to remain in the circle without any mistake are the winners of the game.

Game no. 10 „THE DWARFS THROUGH THE TUNNEL” (I.10)

Description: The children are divided into teams of eight. Four of them stand in a row, the other ones in front of them keep the circles in a vertical position on the ground, at the distance of $1 \mathrm{~m}$, making up a tunnel. At the teacher's whistle, the children from each team go crouched (like little dwarfs) through the tunnel, trying to reach the place where they started from as soon as possible. While moving through the tunnel, they must keep a onearm distance, not being allowed to push one another. The game is repeated several times, the children keeping the circles being changed every time.

Game no. 11 "THE BALL THROUGH THE TUNNEL" (I.11)

Description: The players are lined up in rows, with their feet apart, 3-4 teams making up a tunnel. The first pupil from each team has a ball. At the teacher's whistle, the players with the ball roll it between their legs, the others are careful they help each other by pushing the ball with their hands to the last player from the team. This player catches the ball and runs with it to the right of his row, stands in front of his team with his feet apart and they roll the ball again between the legs. The game continues in this way until the first player from each team comes in front of the row. The team whose first player came to his place the first is the winner. If any player throws the ball out of the tunnel, he must bring it back to the same place and continue. The game can also be played with a medicine ball or with an old stuffed ball.

Game no. 12 "THE SMALL GATE” (I.12)

Description: Two pupils, standing face-to-face, at a distance of 5-6 metres, one of them standing with his feet apart (like a small gate) opens and closes the "gate" by jumping, the other pupil tries to send the ball through the "gate" with his hand or foot. After more repetitions, the roles are changed. The pupil who managed to pass the ball through the "gate" most often will be the winner. The pupils will keep the score by themselves, fact which educates their honesty and fair play.

\section{Results and discussions}

The trial "throw at a vertical target" is the only trial within the assessment system by means of which you can test the level of the coordination skill manifestation indicator (dexterity). The analysis of the results recorded in the initial and final tests of the groups involved in the pilot experiment were statistically processed with the help of the SPSS 23.0 program. This was necessary in order to ensure the objective character of the assessment of the proposed program, represented by movement games, which could influence the improvement of the coordination skill manifestation indicators (dexterity).

The statistical data processing followed two directions: a statistical analysis within the groups (the control and the test group) and a statistical interpretation referring to the comparison of the results obtained in the final trials between groups.

The results obtained in the initial and the final tests by the group of girls are analytically presented in table no. 1.

In the data presented in table no. 1, we may notice the statistical results within the groups of girls. Thus, the results obtained by both groups in the initial tests had close values. The control group achieved an average of successful throws of 1.53, whereas the test group obtained an average value of successful throws of 1.60 . We may notice that the two values are close, fact which indicates a relatively unitary level of the coordination skill indicators.

In the final tests, the control group obtained an average value of successful throws of 2.40 throws, whereas the test group obtained an average value of successful throws of 3.80 
throws. The results obtained in the final tests by the group of girls indicate a positive evolution of the dexterity motor skill manifestation level.

Table 1. The statistical analysis between the initial and the final tests for the groups of girls

\begin{tabular}{|c|c|c|c|c|c|c|c|c|}
\hline \multirow[b]{3}{*}{ Trials } & \multicolumn{8}{|c|}{ Girls } \\
\hline & \multicolumn{4}{|c|}{ The control group $(n=15)$} & \multicolumn{4}{|c|}{ The test group $(n=15)$} \\
\hline & $\begin{array}{c}\text { T.I. } \\
\overline{\mathrm{X}} \pm m\end{array}$ & $\begin{array}{c}\text { T.F. } \\
\overline{\mathrm{X}} \pm m\end{array}$ & $\mathrm{t}$ & $\mathrm{p}$ & $\begin{array}{c}\text { T.I. } \\
\overline{\mathrm{X}} \pm m\end{array}$ & $\begin{array}{c}\text { T.F. } \\
\overline{\mathrm{X}} \pm m\end{array}$ & $\mathrm{t}$ & $\mathrm{p}$ \\
\hline $\begin{array}{l}\text { Throw at a } \\
\text { vertical target (no. } \\
\text { of successful } \\
\text { throws) }\end{array}$ & $\begin{array}{l}1.53 \\
0.99\end{array}$ & $\begin{array}{l}2.40 \\
1.05\end{array}$ & -4.51 & .000 & $\begin{array}{l}1.60 \quad \pm \\
0.98\end{array}$ & $\begin{array}{l}3.80 \\
1.08\end{array}$ & -12.60 & .000 \\
\hline
\end{tabular}

Both groups recorded significant progress, within the group, because the significance level was, in both cases, extremely significant $(p<0,000)$.

Further on, we performed an analysis of the centralised data obtained by the two groups of girls in the final tests. These results are presented in table no. 2.

Table 2. The statistical analysis of the final results obtained by the two groups of girls

\begin{tabular}{|l|c|c|c|c|}
\hline \multirow{2}{*}{ TRIALS } & \multicolumn{3}{|c|}{ GIRLS - Final trial } \\
\cline { 2 - 5 } & $\begin{array}{c}\mathrm{TF} \\
\mathrm{X} \pm m\end{array}$ & $\begin{array}{c}\mathrm{TF} \\
\mathrm{X}\end{array}$ & $\mathrm{t}$ & \multicolumn{1}{c|}{$\mathrm{p}$} \\
\hline $\begin{array}{l}\text { Throw ata vertical target (no. of } \\
\text { successful throws) }\end{array}$ & $2.40 \pm 1.05$ & $3.80 \pm 1.08$ & -3.58 & $.001 *$ \\
\hline
\end{tabular}

${ }^{*} \mathrm{p}<0.001$;

The results presented in the table above clearly indicate that the average value of successful throws recorded by the test group is higher than the average value of the successful throws recorded by the control group. By performing a statistical analysis between the groups and by taking into consideration only the results obtained in the final tests, we may notice that the progress recorded by the test group is strongly significant as compared to the control group $(\mathrm{p}<0.001)$.

Further on, we shall present the results obtained by the groups of boys participating in our study. The level of the performance obtained by them is presented in table no. 3 .

Table 3. The statistical analysis of the final results obtained by the two groups of boys

\begin{tabular}{|c|c|c|c|c|c|c|c|c|}
\hline \multirow[b]{3}{*}{ Trials } & \multicolumn{8}{|c|}{ Boys } \\
\hline & \multicolumn{4}{|c|}{ Control group $(n=14)$} & \multicolumn{4}{|c|}{ Test group $(n=15)$} \\
\hline & $\begin{array}{c}\text { T.I. } \\
\overline{\mathrm{X}} \pm m\end{array}$ & $\begin{array}{c}\mathrm{T} . \mathrm{F} . \\
\overline{\mathrm{X}} \pm m\end{array}$ & $\mathrm{t}$ & $\mathrm{p}$ & $\begin{array}{c}\text { T.I. } \\
\overline{\mathrm{X}} \pm m\end{array}$ & $\begin{array}{c}\text { T.F. } \\
\overline{\mathrm{X}} \pm m\end{array}$ & $\mathrm{t}$ & $\mathrm{p}$ \\
\hline $\begin{array}{l}\text { Throw at a } \\
\text { vertical target } \\
\text { (no. of successful } \\
\text { throws) }\end{array}$ & $\begin{array}{c}2.00 \pm \\
1.03\end{array}$ & $\begin{array}{c}2.92 \pm \\
1.14\end{array}$ & -4.75 & .000 & $\begin{array}{c}1.86 \pm \\
1.06\end{array}$ & $\begin{array}{c}3.40 \pm \\
1.18\end{array}$ & -11.50 & .000 \\
\hline
\end{tabular}

In the initial tests, the average values of successful throws were close. The control group obtained an average value of successful throws of 2, whereas the test group obtained an average value of successful throws of 1.86 . We may notice that the level of the coordination skill indicator was slightly better than that of the control group, even if very close to it. In the final tests, the control group obtained an average value of successful throws of 2.92, whereas the test group obtained an average value of successful throws of 3.40 . In the 
statistical analysis performed within the groups, presented in table 3, we may notice that both groups recorded significant progress in the final tests as compared to the initial tests. Thus, we may state that the influence recorded at the level of the coordination skill manifestation indicators were significant $(p<0,000)$ both in the case of the traditional training means and in the case of using movement games specific to this motor skill.

As in the case of the groups of girls, the statistical analysis was performed on the results recorded in the final test by the two groups of boys. The summary of this statistical analysis is presented in table no.4.

Table 4. The statistical analysis of the final results obtained by the two groups of boys

\begin{tabular}{|l|c|c|c|c|}
\hline \multirow{2}{*}{ TRIALS } & \multicolumn{4}{|c|}{ Boys - Final test } \\
\cline { 2 - 5 } & $\begin{array}{c}\mathrm{TF} \\
\mathrm{X} \pm m\end{array}$ & $\begin{array}{c}\mathrm{TF} \\
\mathrm{X} \pm m\end{array}$ & $\mathrm{t}$ & $\mathrm{p}$ \\
\hline $\begin{array}{l}\text { Throw at a vertical target (no. } \\
\text { of successful throws) }\end{array}$ & $2.92 \pm 1.14$ & $3.40 \pm 1.18$ & -1.09 & $.587^{* *}$ \\
\hline
\end{tabular}

$* * \mathrm{p}>0.05$

In the table above we may notice that the average value of successful throws is higher for the test group as compared to the control group.

Nevertheless, by taking into account the fact that the value of $p$ is $>0.05$, we may state that the difference is not significant from a statistical point of view. Thus, the influence exerted by means of movement games can be considered similar to the influence exerted by other means used in the teaching process. We consider that it is possible for this fact to become manifest at this age group for the group of boys.

\section{Conclusions}

After analysing all the data obtained in the initial and final tests conducted within our pilot experiment, we may draw more categories of conclusions, some of them referring to the means of action, others referring to the structure of the PE lesson and, why not, some others referring to the correlation between the objectives of Physical Education, the learning content and the existing assessment system.

From the point of view of the means of action, we consider that they were efficient because the average values obtained by the group of girls (3,80 successful throws) and by the group of boys ( 3.40 successful throws) were superior to the results obtained by the control groups. As we have shown above, these results were strongly significant for the groups of girls $(p<0.001)$ and not significant enough for the group of boys $(p>.05)$. This aspect of the low significance level for the groups of boys could be due to their age and to the tested motor skill. It is well-known that the coordination skills (dexterity) are closely connected to the emotional aspects, which are not sufficiently developed at this age.

As far as the structure of the PE class is concerned, which is traditionally accepted and promoted in the Romanian school system, it couldn't be applied in its present form. We altered this structure and we replaced the second moment of the lesson, "preparing the body for effort", with movement games, specific to developing coordination skills.

We did this because we couldn't find a possibility to implement these action methods in another moment of the lesson so that we could observe the planning documents approved by the school management for the respective grades. On the other hand, the use of these games, which presuppose attention and focus, were used at the beginning of the lesson, when pupils were rested. Thus, the learning was performed in accordance with the psychopedagogical principles. 
As far as the assessment system is concerned, the trial used is the only one that can assess the development of the coordination skill indicators [24]. The performance aspects are not relevant for the PE activity [20]. Also, the performance assessment is not in accordance with the aims of physical education as a school subject [22, 23].

We consider that the game, as a means of organising teaching activities and as a working method is suitable for this age segment, represented by primary school pupils.

Movement games proved to be attractive and they generated an active participation from the part of the pupils. Group participation and problem-solving in groups or in pairs can represent the premises for achieving the general competences proposed in the curriculum for PE as a school subject.

\section{References}

1. ***, 2011, The Law of National Education, The Official Monitor of Romania, no. 18

2. E. Bota, Contribution of the game in the development of motor skills during the physical education class, Timisoara Physical Education and Rehabilitation Journal, vol. 6, no. 11, pp. 59-63, (2016)

3. N. Carse, Primary teachers as physical education curriculum change agents, European Physical Education Review, Vol. 21, no. 3, pp.309-324, (2015)

4. W. Chen, S. Mason, A. Hypnar, A. Bennett, Assessing Motor Skill Competency in Elementary School Students: A Three-Year Study, Journal of Sport Science \& Medicine, vol. 15, no. 1, pp. 102-110, (2016)

5. J.L. Currie, Teaching Physical Education in Primary School - An integrated health perspective, Publisher: ACER Press, 112-118, (2013)

6. Griggs G., (Ed.), An Introduction to Primary Physical education, Publisher: Routdlege, 151-161, (2012)

7. L.L. Hardy, B.J. O'Hara, K. Rogers, A. St. George, A. Bauman, Contribution of Organized and Nonorganized Activity to Children's Motor Skills and Fitness, Journal of School Health, vol. 84, no. 11, pp. 690-696, (2014)

8. T.M. Iconomescu, Didactics of Physical Education and Sport / Course notes, Publisher: Zigotto, Galati, (2013)

9. M. Jess, N. Carse, J. Keay, The primary physical education curriculum process: more complex than you might think!, Education 3-13 International Journal of Primary, Elementary and Early Years Education, Vol. 44, no. 5, 502-512, (2016)

10. H. Koç, A. Tekin, E. Aykora, Impact of Physical Education Classes on Selected Motor Skills of Children, Middle-East Journal of ScientificResearch, vol. 11, no. 3, pp. 386390, (2012)

11. C. Lämmle, S. Kobel, O. Wartha, T. Wirt, J.M. Steinacker, Intervention effects of a school-based health promotion program on children's motor skills, J Public Health, vol. 24, pp. 185-192, (2016)

12. V. Lyakh, J. Sadowski, Z. Witkowski, Development of coordination motor abilities (CMA) in the system of long-term preparation of athletes, Pol. J. Sport Turism, vol. 18, pp. 187-191, (2011)

13. The Ministry of Education, Research, Youth and Sports, Order 3462 regarding the approval of The organisation and conducting methodology of physical education activities and sport in pre-university education, The Official Monitor of Romania, (2012)

14. G.C. Nobre, P.F.R. Bandeira, N.C. Valentini, The relationship between general perceived motor competence, perceived competence relative to motor skill and actual motor competence in children, J. Phys. Educ. [online]. 2016, vol. 27, pp. 1-12, (2016) 
15. M. O'Sullivan, New directions, new questions: relationships between curriculum, pedagogy, and assessment in physical education, Sport Education and Society, Vol. 18, no.1, pp 1-5, (2013)

16. L. Raudsepp, P .Päll, The relationship between fundamental motor skills and outsideschool physical activity of elementary school children, PediatrExerc Sci., vol. 18, no. 4, pp. 426-435, (2006)

17. C.M. Rus, Communication characteristics during teaching physical education and sport, Sport Science 6 (2), 82-84, (2013)

18. S. Şahin, Education supervisors' views on the new curriculum and its implementation in primary schools, EgitimArastirmalari-Eurasian Journal of Educational Research, Vol. 53, pp. 1-20, (2013)

19. L.G. Talaghir, V. Mîndrescu, M. Ion-Ene, Study regarding the use of movement games and relays in order to improve primary students' strength qualities, SHS Web Conference, ERPA International Congresses on Education, vol. 37, pp. 1-7, (2017)

20. L-G. Talaghir, T.M. Iconomescu, Study regarding the evolution of the primary school curriculum for physical education in Romania in accordance with the assessment system application, INTED2017 Proceeding, 11th International Technology, Education and Development Conference Valencia, Spain, pp 2542-2551, (2017)

21. L-G. Talaghir, Gimnastica acrobatic şcolară, Zigotto Publishing House, pp 6-7, (2015)

22. The Ministry of National Education, Curriculum for Physical Education, The preparatory grade, the first grade and the second grade, Bucureşti, (2013)

23. The Ministry of National Education, Curriculum for Physical Education, The third grade and the fourth grade, Bucureşti, (2014)

24. The Ministry of National Education, Research and Innovation, Curriculum for Physical Education, V - VIII grade, Bucureşt, (2009)

25. N. Wattie, M. Tietjens, J. Schorer, M.C. Ghanbari, B. Strauss, I. Seidel, J. Baker, Does relative age influence motor test performance of fourth grade pupils?, European Physical Education Review, vol. 20, no. 3, pp. 398 - 406, (2014)

26. J. You, A self-study of a national curriculum maker in physical education: challenges to curriculum change, Journal of Curriculum Studies, Vol. 43, no. 1, pp. 87-108, (2011)

27. A. Ungureanu-Dobre, C.M. Rus, L. Mihailescu, Bocoş Muşata, The development of motor capabilities of pupils in the 4th grade through movement games, Literature, Discourse and Multicultural Dialogue, vol. 2, pp. 88-95, (2014). 